\title{
Preoperative dexamethasone reduce postoperative pain and analgesic consumption in patient undergoing laparoscopic cholecystectomy
}

\author{
Archana Har ${ }^{1}$, Ananya Biswas' ${ }^{2}$, Suman Chatterjee ${ }^{3}$, Dilip Kumar Bhowmik ${ }^{1}$, Santi Bhattacharya ${ }^{1}$ and Biswanath Biswas ${ }^{1}$ \\ ${ }^{1}$ Department of Anaesthsiology, IQ City Medical College, Durgapur, West Bengal, India \\ ${ }^{2}$ Department of Anatomy, Malda Medical College, Malda, West Bengal, India \\ ${ }^{3}$ Department of Anaesthsiology, Midnapore Medical College, Midnapore, West Bengal, India
}

\begin{abstract}
Background: Pain after Laparoscopic cholecystectomy is multifactorial, and different treatments have been advocated to provide pain relief. Dexamethasone is best known for its anti inflammatory property that reduces tissue edema during surgical procedure. A single dose of Dexamethasone has been shown to reduce post operative pain scores as well as PONV. We evaluated the efficacy of analgesic effect of single dose (8 mg) of injection Dexamethasone 1 hour before induction of anaesthesia on reducing post operative pain and reduction in opioid usage in laparoscopic cholecystectomy.
\end{abstract}

Materials and methods: In this double blind prospective study 50 patients undergoing laparoscopic cholecystectomy received intravenous Dexamethsone (8 mg) or placebo (normal saline) one hour before induction of GA. Patients received standardised anesthetics, with similar surgical and multimodal analgesic treatment. Total dose of consumed analgesic and pain intensity during first 24 hours postoperative period were evaluated in both groups.

Result: Pain intensity in Dexamethasone group was significantly less than in control group in the first 12 hour post operative period ( $<<0.05$ ). Opioid consumption in Dexamethsone group was significantly less than placebo group $(\mathrm{p}<0.05)$.

Conclusion: We concluded that $8 \mathrm{mg}$ single dose of intravenous Deaxamethasone given at least one hour prior to surgery is a safe, effective and inexpensive choice to control post operative pain and at the same time to reduce opiod consumption in comparison with placebo.

\section{Introduction}

Laparoscopic cholecystectomy (LC) is a standard treatment for cholelithiasis, due to decreased post operative trauma and less side effects [1]. However, pain is still considered the most common complaint and the reason of prolonged hospitalisation, more morbidity and delayed functional recovery after LC $[2,3]$. There are many causes of laparoscoic induced pain [4], of which stretching of intra abdominal organs, peritoneal inflammation and phrenic nerve irritation by residual carbon di-oxide $\left(\mathrm{CO}_{2}\right)$ in peritoneal cavity are important. Pain is more severe on the day of operation and the following day after LC [5]. Dexamethasone is a powerful anti-inflammatory drug with a long half life and its administration is considered safe for periods shorter than 2 weeks even in amount above the physiological doses [6].

Several clinical trials in many different surgical procedures evaluated the effects of a single dose of dexamethasone administered on post operative pain but have inconsistent findings [7,8]. Furthermore, there are very few articles on use of preoperative Dexamethasone for postoperative pain relief in the Indian Scenario. We therefore performed this study to observe the efficacy of use of preoperative Dexamethasone in reducing post operative pain as well as analgesic requirements in patients undergoing LC.

\section{Material and method}

After taking institutional approval and informed consent 100 patients aged 18-60 yrs of both sexes ASA I and II scheduled for LC under general anaesthesia (GA) were selected for this study conducted at I Q City Medical College and Hospital, Durgapur. Patients with hepatic and renal insufficiency; history of corticosteroid hypersensitivity; previous gastric ulcer; diabetes mellitus; receiving any corticosteroid, immunosuppressive analgesics or opioid medications were excluded from the study. Visual Analogue Score (VAS) where 0 means no pain, 10 means worst possible pain were explained to all patients during their pre-operative visit. Patients were randomly allocated using a random number table and sealed envelope technique to receive intervenously one of two treatment regimes: Dexamethasone $8 \mathrm{mg}$ (Group D) or normal saline as placebo (Group S). 50 patients in each group received either of the drugs.

Study medications (2 $\mathrm{ml}$ each) were prepared by personnel not involved in the study in identical $2 \mathrm{ml}$ covered syringes to ensure blinding of the anesthetists and patients. These drugs were

Correspondence to: Suman Chatterjee, Department of Anaesthsiology, Midnapore Medical College, Midnapore, BC 103, Salt Lake, Kolkata-700064, India, E-mail: ahmeda1995@yahoo.com

Key words: laparoscopic cholecystectomy, dexamethasone, post operative pain, analgesic consumption

Received: April 05, 2015; Accepted: May 07, 2015; Published: May 10, 2015 
administered intervenously one hour before induction of GA. Patients and investigators who collected post operative data were blinded to the study drugs administered.

Patients received tablet alprazolam $0.5 \mathrm{mg}$ orally on night before operation and were fasted for at least 6 hours before surgery. All subjects were hydrated with $10 \mathrm{ml} \cdot \mathrm{kg}^{-1}$ of Ringer's lactate (RL). Anaesthesia was induced with fentanyl $2 \mathrm{mcg} \cdot \mathrm{kg}^{-1}$, followed by propofol $2 \mathrm{mg} \cdot \mathrm{kg}^{-1}$. Intravenous atracurium $(0.6 \mathrm{mg} / \mathrm{kg})$ was given intravenously to facilitate oro-tracheal intubation. Anaesthesia was maintained with isoflurane ( $1 \%$ inspired concentration, along with nitrous oxide $66 \%$ in oxygen) with controlled ventilation adjusted to keep the end tidal $\mathrm{CO}_{2}$ at around 35 to $45 \mathrm{~mm} \mathrm{Hg}$. Muscle relaxation for pneumoperitonium and surgical procedures was provided with additional doses of atracurium. Nasogastric (NG) tube was passed to empty the stomach content by suction. Before tracheal extubation NG tube was resuctioned and removed. During Laparoscopy the intraabdominal pressure maintained at 8 to $12 \mathrm{~mm} \mathrm{Hg}$ by a $\mathrm{CO}_{2}$ insuflator and patient were placed in 15 to 20 degree head up position with slight left lateral tilt. After removal of the gall bladder injection ondansetron $8 \mathrm{mg}$ was administered intravenously. Patients were monitored during GA by continuous ECG, NIBP, pulse oximetry and capnometry. At the completion of surgery residual neuromuscular blockade was antagonised with neostigmine $\left(0.05 \mathrm{mg} \cdot \mathrm{kg}^{-1}\right)$ and glycopyrolate $(0.01$ mg. $\left.\mathrm{kg}^{-1}\right)$ administered intrvenously.

Trachea was extubated once the patient was awake. All patients received supplementation of oxygen ( 3 litres/min) by a face mask in the post operative period for 2 hours and were monitored continuously in the recovery room. After 2 hours the patients were sent to their respective wards. Pain intensity and capillary glucose concentration was measured at $0,1,2,4,6,12$ and 24 hours postoperatively. Pain was classified as mild - 0 to 3 , moderate -4 to 7 and severe -8 to 10 based on the VAS score of the patients. If VAS score was $\geq 3$, pethidine 1 mg.kg-1 was administered intravenously. Total consumed meperidine during the first 24 hours postoperative period was recorded. Details of adverse effects were recorded during study period by attending anaesthesiologist.

\section{Statistical analysis}

Considering VAS scores from previous studies and power (1beta $)=75 \%$ and level of significance $=5 \%$ sample size was calculated 35 for each arm. To increase the power of the study further we choose 50 patients in each group (Group D and S respectively). All of the statistical data was reported as mean $\pm \mathrm{SD}$. One way ANOVA was used for comparisons of data which are commonly expected to be normally distributed, e.g. demographics, duration of analgesia, and intraoperative and postoperative analgesic use. Chi-square and Kruskal-Wallis tests were used for postoperative VAS scoring.

\section{Results}

In this study 100 patients were divided into two groups receiving either $2 \mathrm{ml}$ normal saline (group S) or Dexamethasone 8mg (group D) in identical $2 \mathrm{ml}$ covered syringes, 1 hour before GA.

There were no difference between the two groups regarding demographic characteristics (in terms of age, sex height, weight and ASA grade) and duration of surgery ( $>0.05)$ (Table 1).

The meperidine consumption in the Dexamethasone group was significantly less $(135.4 \pm 25.7$ vs. $228.8 \pm 21.5$ milligrams respectively; Table 2, Figure 1).
Table 1. Demographic Data.

\begin{tabular}{|l|c|c|}
\hline & Group D (n = 50) & Group S (n = 50) \\
\hline Age (years) & $46.4 \pm 10$ & $44.8 \pm 8$ \\
\hline Height $(\mathrm{cm})$ & $143.7 \pm 4$ & $140.9 \pm 5$ \\
\hline Weight $(\mathrm{kg})$ & $54.2 \pm 6$ & $51.6 \pm 8$ \\
\hline BMI & $26.2 \pm 0.6$ & $26.4 \pm 0.4$ \\
\hline ASA I/ASA II & $42 / 8$ & $43 / 7$ \\
\hline Duration of surgery $(\mathrm{min})$ & $47.8 \pm 26$ & $50.1 \pm 30$ \\
\hline
\end{tabular}

${ }^{*} p>0.05$

Table 2. Meperidine consumed per patient during study period (mean \pm std. deviation).

\begin{tabular}{|l|c|c|}
\hline & Group S (n= 50) & Group D (n= 50) \\
\hline Meperidine consumption (mg) & $228.8 \pm 21.5$ & $135.4 \pm 25.7^{*}$ \\
\hline${ }^{*} \mathrm{p}<0.05$ &
\end{tabular}

Table 3. Comparison of pain intensity amongst two study groups.

\begin{tabular}{|l|r|r|}
\hline VAS & Group D & Group S \\
\hline On arrival to PACU (0 hour) & $5.4 \pm 2.5$ & $5.3 \pm 2.7$ \\
After 1hour & $3.8 \pm 1.2$ & $5.4 \pm 2.5^{*}$ \\
After 2 hour & $3.2 \pm 1.4$ & $5.5 \pm 2.7^{*}$ \\
After 4 hour & $3.1 \pm 1.5$ & $5.20 \pm 1.4^{*}$ \\
After 6 hour & $2.9 \pm 1.7$ & $4.8 \pm 2.9^{*}$ \\
After 12 hour & $2.8 \pm 1.3$ & $4.2 \pm 2.4^{*}$ \\
After 24 hour & $2.9 \pm 1.4$ & $2.8 \pm 1.2$ \\
\hline
\end{tabular}

\begin{tabular}{l|l|l|} 
After 24 hour & $2.9 \pm 1.4$ & $2.8 \pm 1.2$ \\
\hline
\end{tabular}

Data are presented as numbers or mean $\pm S D$, *signifies a $p$ value of significance $(<0.05)$

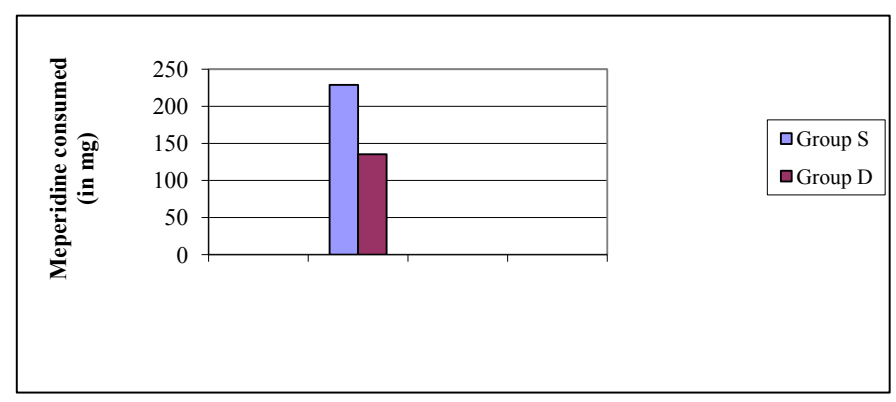

Figure 1. Average postoperative pethidine consumption in the two groups.

The mean post operative pain intensity based on VAS score for the first 12 hours in recovery room and ward in group D was significantly lower compared with group $S(\mathrm{p}<0.05)$, Table 3 . However, at 24 hours the VAS scores of the two groups were similar. There were no adverse events in any patient.

\section{Discussion}

Our study result revealed that a single intravenous dose of preoperative dexamethasone $8 \mathrm{mg}$ reduced intensity of postoperative pain in first 12 hours in comparison with placebo and it also decreases total consumption of post operative analgesic.

The results are similar with studies conducted by Fukami et al. [8] and Lim et al. [9] The mechanism of pain relief by dexamethasone is mainly provided by peripheral suppression of phospolipase enzyme, thereby significantly decreasing the products of cyclooxygenase and lipooxygenase pathways in the inflammatory response $[8,10]$. Additionally dexamethasone reduced bradykinin which reinforces pain in the inflamed tissues and operated area, and also the decreased concentration of nerve proteins secreted from the peripheral nerve system are involved in the analgesic effect [11]. 
Postoperative pain after laparoscopic cholecystectomy is induced by multiple factors i.e. from skin incision, visceral pain, diaphragmatic irritation, different individual characteristics, nature of underlying diseases, surgical factors and type and volume of gas and also induced intra abdominal pressure. Hence the multimodal approaches are considered for post operative pain relief $[12,13]$. The timings of steroid administration is important to reducing postoperative pain, as initiation of its biological effect is one or two hour of its injection [14]. The dose of dexamethasone $8 \mathrm{mg}$ one hour before induction was based on previous reports showing a decrease in postoperative pain $[9,15]$.

We measured the pain intensity of the patient at 12 hours followed by 24 hours after the operation. While pain relief was significantly more at 12 hours with Dexamethasone, it was similar at 24 hours compared with normal saline, a finding similar to the study of Mohtadi A et al. [15].

A limitation of this study was that we did not measure pain intensity at any time between 12 to 24 hours, so the exact duration of dexamethasone effect postoperatively could not be ascertained from our study. We also did not study of serum concentration of dexamethasone and stress hormones. We only studied perioperative glucose levels which was insignificant in our study.

With use of steroids complication such as delays recovery, postoperative infection, glucose intolerance and gastric mucosa ulcer can occur [9]. Sauerland et al. [16] reported in their meta analysis that there was no significant increase in complications when they used 15$30 \mathrm{mg} \cdot \mathrm{kg}^{-1}$ of methylprednisolone in one dose which is fifty times the amount of dexamethasone used in our study. In our study we did not find any complication related to use of a single dose of dexamethasone. To conclude, $8 \mathrm{mg}$ dexamethasone pre operatively helps in better postoperative pain control as well as reduced opioid consumption.

\section{References}

1. Mealy K, Gallagher H, Barry M, Lennon F, Traynor O, et al. (1992) Physiological and metabolic responses to open and laparoscopic cholecystectomy. Br J Surg 79: 10611064. [Crossref]

2. Hessami MA, Yari M (2012) Granisetron versus dexamethasone in prophylaxis of nausea and vomiting after laparoscopic cholecystectomy. Anesth Pain Med 2: 81-84. [Crossref]
3. Lepner U, Goroshina J, Samarütel J (2003) Postoperative pain relief after laparoscopic cholecystectomy: a randomised prospective double-blind clinical trial. Scand J Surg 92: 121-124. [Crossref]

4. Golubovic S, Golubovic V, Cindric-Stancin M, Tokmadzic VS (2009) Intraperitoneal analgesia for laparoscopic cholecystectomy: bupivacaine versus bupivacaine with tramadol. Coll Antropol. 33: 299-302. [Crossref]

5. Bisgaard T, Kehlet H, Rosenberg J (2001) Pain and convalescence after laparoscopic cholecystectomy. Eur J Surg 167: 84-96. [Crossref]

6. De Oliveira GS Jr, Ahmad S, Fitzgerald PC, Marcus RJ, Altman CS, Panjwan AS, et al. (2011) Dose ranging study on the effect of preoperative dexamethasone on postoperative quality of recovery and opioid consumption after ambulatory gynaecological surgery. Br J Anaesth. 107: 362-371. [Crossref]

7. Feroci F, Rettori M, Borrelli A, Lenzi E, Ottaviano A, et al. (2011) Dexamethasone prophylaxis before thyroidectomy to reduce postoperative nausea, pain, and vocal dysfunction: a randomized clinical controlled trial. Head Neck 33: 840-846. [Crossref]

8. Fukami Y, Terasaki M, Okamoto Y, Sakaguchi K, Murata T, et al. (2009) Efficacy of preoperative dexamethasone in patients with laparoscopic cholecystectomy: a prospective randomized double-blind study. J Hepatobiliary Pancreat Surg. 16: $367-$ 71. [Crossref]

9. Lim SH, Jang EH, Kim MH, Cho K, Lee JH, et al. (2011) Analgesic effect of preoperative versus intra-operative dexamethasone laparoscopic cholecystectomy with multimodal analgesia. Korean J Anesthesiol. 61: 315-319. [Crossref]

10. Callery MP (2003) Preoperative steroids for laparoscopic surgery. Ann Surg 238: 661662. [Crossref]

11. Hong D, Byers MR, Oswald RJ (1993) Dexamethasone treatment reduces sensory neuropeptides and nerve sprouting reactions in injured teeth. Pain 55: 171-181. [Crossref]

12. Sarvestani AS, Amini S, Kalhor M, Roshanravan R, Mohammadi M, et al. (2013) Intraperitoneal hydrocortisone for pain relief after laparoscopic cholecystectomy. Saudi J Anaesth 7: 14-17. [Crossref]

13. Bisgaard T, Klarskov B, Rosenberg J, Kehlet H (2001) Characteristics and prediction of early pain after laparoscopic cholecystectomy. Pain 90: 261-269. [Crossref]

14. Murphy GS, Szokol JW, Greenberg SB, Avram MJ, Vender JS, et al. (2011) Preoperative dexamethasone enhances quality of recovery after laparoscopic cholecystectomy: effect on in-hos-pital and post-discharge recovery outcomes. Anesthesiology 114: 882890. [Crossref]

15. Mohtadi A, Nesioonpour S, Salari A, Akhondzadeh R, Rad BM, et al. (2014) The effect of single-dose administration of dexamethasone on postoperative pain in patients undergoing laparoscopic cholecystectomy. Anesth Pain Med 4: e1787. [Crossref]

16. Sauerland S, Nagelschmidt M, Mallmann P, Neugebauer EA (2000) Risks and benefits of preoperative high dose methylprednisolone in surgical patients: a systematic review. Drug Saf 23: 449-461. [Crossref]

Copyright: (C2015 Har A. This is an open-access article distributed under the terms of the Creative Commons Attribution License, which permits unrestricted use, distribution, and reproduction in any medium, provided the original author and source are credited. 